\title{
The Effect of Nano Zinc Oxide Particles on Color Stability of MDX4-4210 Silicone Prostheses
}

\author{
Dittaya Charoenkijkajorn ${ }^{1}$ Sasiwimol Sanohkan ${ }^{1}$ \\ ${ }^{1}$ Department of Prosthetic Dentistry, Faculty of Dentistry, \\ Prince of Songkla University, Songkhla, Thailand

\begin{abstract}
Address for correspondence Sasiwimol Sanohkan, DDS, PhD, Prince of Songkla University, Hat Yai, Songkhla 90110, Thailand (e-mail: ssasiwimol@yahoo.com).
\end{abstract} \\ Department of Prosthetic Dentistry, Faculty of Dentistry,
}

Eur J Dent:2020;14:525-532

\begin{abstract}
Keywords

- nano zinc oxide

- facial silicone

- artificial aging

- color stability

Objective This article aimed to study the effect of different concentrations of nano zinc oxide particles on the color change of MDX4-4210 facial silicone elastomer after artificial aging.

Materials and Methods Silicone specimens $(N=150)$ were fabricated by incorporating intrinsic pigments and divided into three groups-white, yellow, and red, each group consisting of 50 specimens $(n=50)$. In each color, specimens were subdivided into five subgroups according to the quantity of zinc oxide nanoparticles $(0,0.5,1.0$, 1.5 , and $2.0 \%$ weight), where the $0 \%$ weight served as the control in each group. All specimens were then subjected to artificial aging using an accelerated aging machine chamber for $12,24,48$, and 72 hours. $L^{*} a^{*} b^{*}$ values of specimens were noted after a different aging period by a spectrophotometer and $\Delta E^{*}$ was calculated.

Statistical Analysis Two-way repeated analysis of variance (ANOVA) was done to examine the effects under test conditions (concentration and aging time) of each color group. Then color, concentration, and the aging period were subjected to threeway repeated ANOVA to investigate the effects of different colors and concentrations on $\Delta E^{*}$. Bonferroni's test was performed to identify differences between groups. The significant level was at $p=0.05$.

Results The control group showed significantly higher $\Delta E^{*}$ values than the test groups. The $1.5 \%$ test group showed significantly lower $\Delta E^{*}$ compared with the others. The 0.5 to $2.0 \%$ of nano zinc oxide significantly decreased the color change of the silicone elastomer $(p<0.05)$, but there were no significant differences among groups. Conclusions Incorporation of $1.5 \%$ of nano zinc oxide can improve the color stability of silicone prosthesis (MDX4-4210).
\end{abstract}

\section{Introduction}

The goal of maxillofacial prosthodontics is to rehabilitate patients who suffer due to cancer, trauma, or congenital disorders. Resection of head and neck cancer leave defects that compromise the function, psychological, and esthetic aspects of a patient. An extraoral prosthesis restores ocular, orbital, auricular, nasal, and facial defects. Silicone elastomeric materials are widely used in patients with extraoral defects to restore the missing structure and promotes esthetics and confidence in the patient. ${ }^{1-4}$ Clinically, MDX4-4210 is commonly used for the fabrication of various prosthesis as the prosthesis looks natural and skin-like appearance with detail reproduction. ${ }^{5}$ Skin tones in silicone prosthesis can be created by mixing the three primaries-yellow, red, and blue in different ratios. ${ }^{6}$ Unfortunately, longevity is poor due to the color change. ${ }^{1}$ The color change is a major problem among maxillofacial defects patients who have their prosthesis remade..$^{1-4}$ There are various color systems to assess the chromatic differences, such as the Munsell color system and the Commission Internationale de I'Eclairage (CIE) L*a*b*
License terms

10.1055/s-0040-1713058

ISSN 1305-7456. 
color system. ${ }^{7}$ In addition, Cantor et $\mathrm{al}^{8}$ mentioned the use of reflectance spectrophotometry, color, and optical density to evaluate the color stability. Watson et $\mathrm{al}^{9}$ mentioned that following exposure to water and ultraviolet (UV) light, the average color stability of an implant-retained auricular silicone prosthesis was 21 months. However, color change of a facial silicone prosthesis comprised of several factors including UV ray exposure, weathering, vulcanization process, inherent pigment stability, the cleaning solution, personal habits, and environmental staining. ${ }^{10,11}$ Incorporation of nanoparticles, such as zinc oxide, titanium dioxide, and barium sulfate, is a new method for protecting degradation. ${ }^{2}$ There are only a few studies reporting about the effects of nano zinc oxide on the color stability of polymers. ${ }^{12}$ This work aimed to study the effect of different concentrations $(0,0.5,1.0,1.5$, and $2.0 \%$ by weight) of nano zinc oxide particles on the color stability of MDX4-4210 silicone elastomer after artificial aging.

\section{Materials and Methods}

\section{Specimen Preparation}

Ethical approval was provided by the Human Research Ethics Committee of Faculty of Dentistry, Prince of Songkla University (EC6105-20-P-LR). Materials used in this study are presented in -Table 1. Disc-shaped specimens ( $20 \mathrm{~mm}$ in diameter and $3 \mathrm{~mm}^{13}$ thick, - Fig. 1) of silicone elastomers (Silastic MDX 4-4210; Dow Corning Corporation, Auburn, Michigan, United States) were fabricated according to the manufacturer's instructions. Silicone specimens $(N=150)$ were fabricated by incorporating intrinsic pigments $(0.2 \%$ of white, red, and yellow) $)^{14}$ and divided into three groups-white, yellow, and red. Each group consisting of 50 specimens $(n=50)$. In each color, specimens were subdivided into five subgroups according to the quantity of zinc oxide nanoparticles $(0,0.5,1.0,1.5$, and $2.0 \%$ weight) where the $0 \%$ weight served as the control in each group ( - Fig. 2). After that, silicone was loaded into the stainless-steel flask with a plastic syringe. The flask was closed and clamped with ratcheting clamp and placed in room temperature for 3 days to complete polymerization. After vulcanization, the flash around the specimens was trimmed by a sharp scalpel at room temperature. The specimens were free of voids and surface defects, totaling of 150 specimens.

\section{Test Conditions}

To evaluate the baseline color in the CIE L*a*b* system, a spectrophotometer (Color Quest XE; Hunter Laboratory, Reston, Virginia, United States) was used. The spectrophotometer was calibrated with a standard white tile. The specimens were tested on a white background. After baseline readings, all specimens were placed in an accelerated weathering chamber (QUV Accelerated Weathering Tester, Q-Laboratory Inc.; Ohio, United States) to simulate routine use of the maxillofacial prosthesis when exposed to light, water, temperatures, and humidity by following the 2012 America Standard of Testing Material, G154-12a, Standard Practice for Operating Fluorescent Ultraviolet (UV) Lamp Apparatus for Exposure of Nonmetallic Materials (UVA Lamp-340, Irradiance $0.89 \mathrm{~W} / \mathrm{m}^{2} / \mathrm{nm}$, wavelength $340 \mathrm{~nm}$, exposure cycle 8 hours at $60( \pm 3)^{\circ} \mathrm{C}$ Black Panel Temperature; 4 hours Condensation at $50( \pm 3)^{\circ} \mathrm{C}$ Black Panel Temperature) for 12 , 24,48 , and 72 hours. CIE L*a*b* color values were measured following each artificial aging period in the same position by using an acrylic jig. The color change $\left(\Delta E^{*}\right)$ was calculated using $\mathrm{L}^{*}, \mathrm{a}^{*}$, and $\mathrm{b}^{*}$ values using the following formula ${ }^{15-17}$ :

$$
\Delta E^{*} *\left[\left(\Delta L^{*}\right)^{2}+\left(\Delta a^{*}\right)^{2}+\left(\Delta b^{*}\right)^{2}\right]^{1 / 2}
$$

\section{Statistical Analysis}

Statistics were computed using the Statistical Package for Social Science (SPSS) software (version 24; SPSS Inc., Chicago, Illinois, United States). First, $\Delta E^{*}$ values of the white, yellow, and red groups were subjected to two-way repeated analysis of variance (ANOVA) to examine the effects under test conditions (concentration and aging time) of each color group. Then color, concentration, and the aging period were subjected to three-way repeated ANOVA to investigate the effects of different colors and concentrations on $\Delta E^{*}$. Then, $\Delta E^{*}$ values were calculated with repeated ANOVA measures where concentration is the main factor, pigments are covariance, and

Table 1 Materials used in this study

\begin{tabular}{|l|l|l|l|}
\hline Products & $\begin{array}{l}\text { Material type, composition, and } \\
\text { instruction }\end{array}$ & Manufacturer & Batch no. \\
\hline $\begin{array}{l}\text { Silastic MDX4-4210 } \\
\text { medical-grade elastomer }\end{array}$ & $\begin{array}{l}\text { Room temperature vulcanized addition cure } \\
\text { silicone; elastomer component: dimethyl- } \\
\text { siloxane polymer, reinforcing silica, and } \\
\text { platinum catalyst curing agents: dimethyl- } \\
\text { siloxane polymer, inhibitor, and siloxane } \\
\text { cross-linker }\end{array}$ & $\begin{array}{l}\text { Dow Corning Corp; Auburn, } \\
\text { MI, USA }\end{array}$ & 0009212786 \\
\hline $\begin{array}{l}\text { Functional intrinsic Skin } \\
\text { colors-White }\end{array}$ & Silicone Coloring System \\
\hline $\begin{array}{l}\text { Functional intrinsic Skin } \\
\text { colors-Red }\end{array}$ & Silicone Coloring System & Factor II Inc.; Lakeside, Arizona & TL10610 \\
\hline Functional & Silicone Coloring System & Factor II Inc.; Lakeside, Arizona & TK021209) \\
\hline intrinsic Skin colors-Yellow & Nano zinc oxide particle $(200 \mu \mathrm{m})$ & Lakeside, Arizona & TS042010 \\
\hline Nano zinc oxide & Mrizona Recipes & SY47LF \\
\hline
\end{tabular}




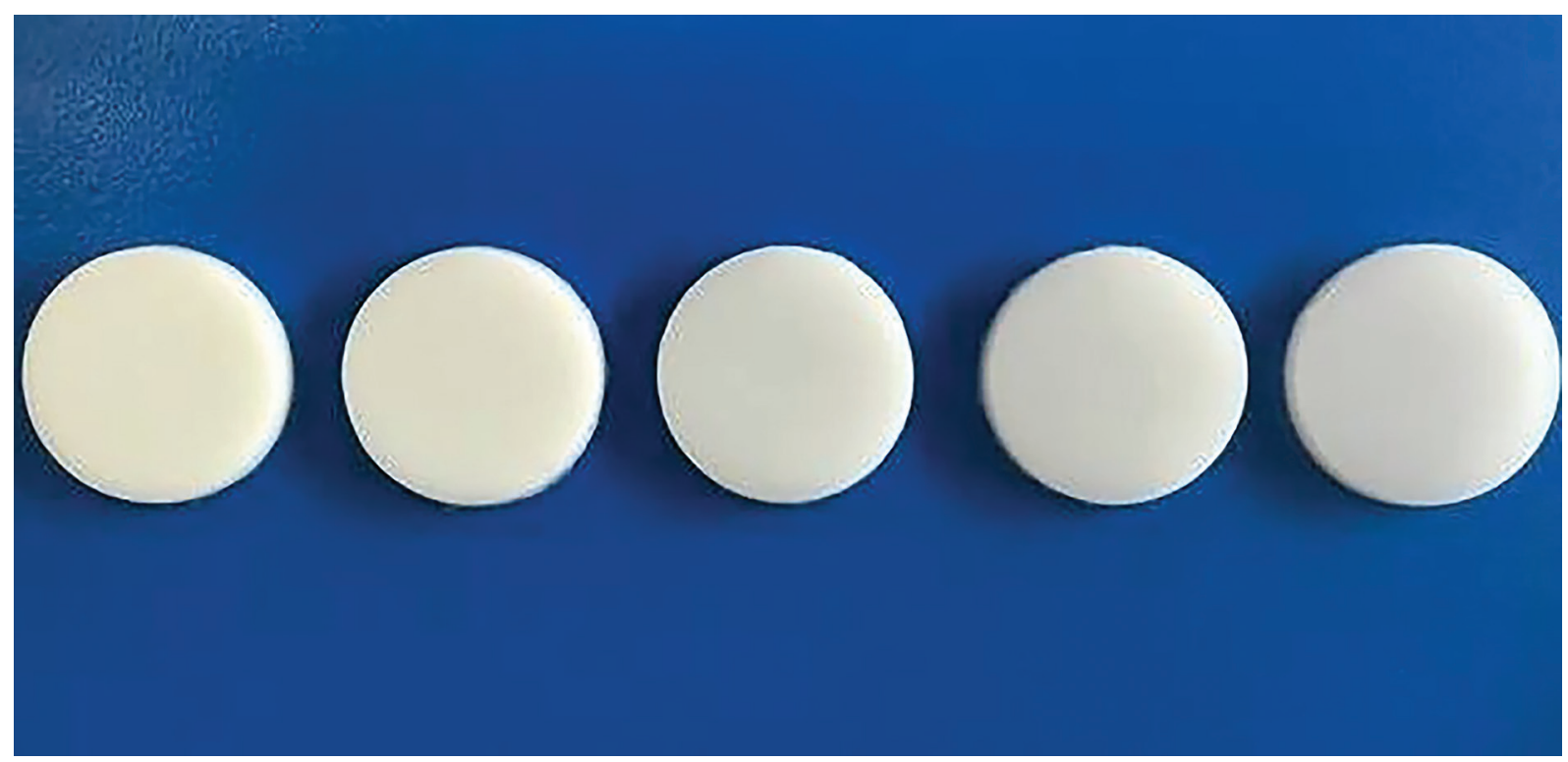

Fig. 1 Specimens of silicone with $0.2 \%$ functional intrinsic white, $0.5,1,1.5$, and $2 \%$ nano zinc oxide by weight (from left to right).

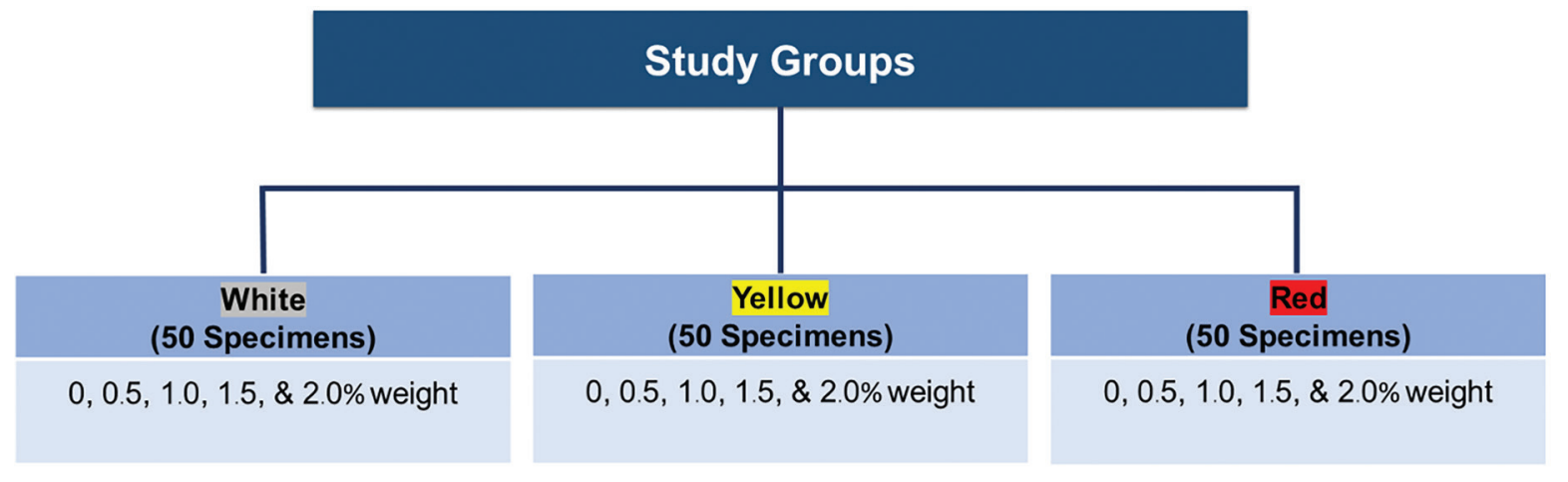

$0 \%=$ Control in each group (White, Yellow, Red)

Fig. 2 Study groups mentioned in this study with subgroups.

aging time is the repeated measure. For the significant different data, Bonferroni's test was performed to identify differences between groups. The level of significance was 0.05 .

\section{Results}

- Tables 2 to 4 show the mean (standard deviation [SD]) values for the color difference $\left(\Delta E^{*}\right)$ in the white, yellow, and red group. The results revealed that artificial aging caused considerable color changes in the polymerized silicone elastomers. This was demonstrated as statistically and significantly increase in $\Delta E$ values at every time point $(12,24,48$, and 48 hours). It showed that there were significant differences among the concentrations and the aging period ( $p<0.05$ ).

For the white group ( - Table 2 ), the $1.5 \%$ group showed the lowest color change $\left(\Delta E^{*}\right)$ which was significantly different from others $(p<0.05)$. Between the 1.0 and $2.0 \%$ groups, it showed no significant differences but there was significantly less color change than the 0 and $0.5 \%$ groups. In the yellow group (-Table 3), the 1.5 and $2.0 \%$ groups had significantly less color change than the other groups. There was no significant difference between the $0,0.5$, and $1.0 \%$ groups. For the red group ( - Table 4 ), there was no significant difference in color change between the 0.5 and $1.5 \%$ groups.

Three-way repeated ANOVA of $\Delta E^{*}$ (- Table 5) revealed the significant difference among concentration, color, time, and interactions. The control group ( $0 \%$ of the particle) had the greatest color change and the $1.5 \%$ group showed the least color change. There was no significant difference in the $0.5,1.0$, and $1.5 \%$ groups. For the effect of color, there was a significant difference among colors, the white color had the greatest color change but there was no significant difference between the yellow and red group.

The mean (SD) values for the color difference $\left(\Delta E^{*}\right)$ at each time point are shown in - Fig. 3. The control group had a significantly higher $\Delta E^{*}$ values than the test groups. Among the 
Table 2 Mean values (SDs) of $\Delta E^{*}$ of white group in each concentration over aging period

\begin{tabular}{|l|l|l|l|l|}
\hline \multicolumn{1}{|c|}{ Group } & $12 \mathrm{~h}$ & $24 \mathrm{~h}$ & $48 \mathrm{~h}$ & $72 \mathrm{~h}$ \\
\hline White - control & & & & \\
\hline White - 0.5\% ZnO & $0.60(.07) \mathrm{Aab}$ & $0.54(0.06) \mathrm{Bab}$ & $0.98(0.06) \mathrm{Cab}$ & $1.12^{\mathrm{a}}(0.06) \mathrm{Cab}$ \\
\hline White - $1.0 \% \mathrm{ZnO}$ & $0.55(0.06) \mathrm{Aa}$ & $0.63(0.07) \mathrm{Ba}$ & $1.10(0.08) \mathrm{Ca}$ & $1.1^{\mathrm{a}}(0.06) \mathrm{Ca}$ \\
\hline White - $1.5 \% \mathrm{ZnO}$ & $0.41(0.06) \mathrm{Ab}$ & $0.58(0.04) \mathrm{Bb}$ & $0.73(0.05) \mathrm{Cb}$ & $0.78(0.04) \mathrm{Cb}$ \\
\hline White - 2.0\% ZnO & $0.41(0.05) \mathrm{Aa}$ & $0.76(0.04) \mathrm{Ba}$ & $1.0(0.06) \mathrm{Ca}$ & $1.10^{\mathrm{a}}(0.06) \mathrm{Ca}$ \\
\hline
\end{tabular}

Abbreviation: SD, standard deviation.

Note: Tukey test with a level of significance of 0.05 . Groups with the same superscript uppercase letter per column or lowercase letter per row are not significantly different $(p>0.05)$.

avalues of $\Delta E^{*}>1.0$ a.

Table 3 Mean values (SDs) of $\Delta \mathrm{E}^{*}$ of yellow group in each concentration over aging period

\begin{tabular}{|l|l|l|l|l|}
\hline \multicolumn{1}{|c|}{ Group } & $12 \mathrm{~h}$ & $24 \mathrm{~h}$ & $48 \mathrm{~h}$ & $72 \mathrm{~h}$ \\
\hline Yellow - control & $0.48(0.05) \mathrm{Aa}$ & $0.71(0.07) \mathrm{Bb}$ & $0.98(0.10) \mathrm{Ca}$ & $1.40^{\mathrm{a}}(0.02) \mathrm{Da}$ \\
\hline Yellow - 0.5\% ZnO & $0.44(0.07) \mathrm{Aa}$ & $0.70(0.10) \mathrm{Ba}$ & $0.79(0.05) \mathrm{Ca}$ & $0.98(0.03) \mathrm{Da}$ \\
\hline Yellow - 1.0\% ZnO & $0.62(0.06) \mathrm{Aa}$ & $0.77(0.10) \mathrm{Ba}$ & $0.85(0.05) \mathrm{Ca}$ & $1.04-(0.04) \mathrm{Da}$ \\
\hline Yellow - 1.5\% ZnO & $0.21(0.01) \mathrm{Ab}$ & $0.43(0.05) \mathrm{Bb}$ & $0.48(0.06) \mathrm{Cb}$ & $0.62(0.03) \mathrm{Db}$ \\
\hline Yellow - 2.0\% ZnO & $0.35(0.06) \mathrm{Ab}$ & $0.37(0.04) \mathrm{Bb}$ & $0.51(0.07) \mathrm{Cb}$ & $0.69(0.03) \mathrm{Db}$ \\
\hline
\end{tabular}

Abbreviation: SD, standard deviation.

Note: Tukey test with a level of significance of 0.05 . Groups with the same superscript uppercase letter per column or lowercase letter per row are not significantly different $(p>0.05)$.

avalues of $\Delta E^{*}>1.0$ a.

Table 4 Mean values (SDs) of $\Delta \mathrm{E}^{*}$ of red group in each concentration over aging period

\begin{tabular}{|l|l|l|l|l|}
\hline \multicolumn{1}{|c|}{ Group } & $12 \mathrm{~h}$ & $24 \mathrm{~h}$ & $48 \mathrm{~h}$ & $72 \mathrm{~h}$ \\
\hline Red - control & & & & \\
\hline Red - 0.5\% $\mathrm{ZnO}$ & $0.57(0.3) \mathrm{Aa}$ & $0.92(0.3) \mathrm{Aa}$ & $1.17^{\mathrm{a}}(0.1) \mathrm{Ba}$ & $1.20^{\mathrm{a}}(0.4) \mathrm{Ba}$ \\
\hline Red - 1.0\% $\mathrm{ZnO}$ & $0.30(0.3) \mathrm{Ab}$ & $0.38(0.4) \mathrm{Ab}$ & $0.73(0.3) \mathrm{Bb}$ & $0.86(0.3) \mathrm{Bb}$ \\
\hline Red - 1.5\% ZnO & $0.30(0.3) \mathrm{Ab}$ & $0.49(0.4) \mathrm{Ab}$ & $0.68(0.4) \mathrm{Bb}$ & $0.80(0.3) \mathrm{Bb}$ \\
\hline Red - 2.0\% ZnO & $0.60(0.3) \mathrm{Aa}$ & $0.64(0.6) \mathrm{Aa}$ & $0.87(0.4) \mathrm{Ba}$ & $0.88(0.3) \mathrm{Ba}$ \\
\hline
\end{tabular}

Abbreviation: SD, standard deviation.

Note: Tukey test with a level of significance of 0.05 . Groups with the same superscript uppercase letter per column or lowercase letter per row are not significantly different $(p>0.05)$.

Values of $\Delta E^{*}>1.0$ a.

Table 5 ANOVA of $\triangle E^{*}$ for five concentrations and colors and their interactions for aging periods

\begin{tabular}{|c|c|c|c|c|c|}
\hline Source & $d f$ & Sum of squares & Mean square & $F$ & $p$-Value \\
\hline Concentration & 4 & 5.729 & 1.432 & 20.304 & 0.000 \\
\hline Color & 2 & 1.430 & 0.715 & 10.138 & 0.000 \\
\hline Concentration $\times$ Color & 8 & 5.233 & 0.654 & 9.272 & 0.000 \\
\hline Aging & 3 & 20.926 & 6.975 & 248.978 & 0.000 \\
\hline Aging $\times$ Concentration & 12 & 0.736 & 0.061 & 2.189 & 0.012 \\
\hline Aging $\times$ Color & 6 & 0.894 & 0.149 & 5.319 & 0.000 \\
\hline Aging $\times$ Concentration $\times$ Color & 24 & 1.673 & 0.070 & 2.488 & 0.000 \\
\hline
\end{tabular}

Abbreviations: ANOVA, analysis of variance; df, degrees of freedom.

Note: Significantly different at $p<0.05$. Repeated measure, $p>0.05$. 


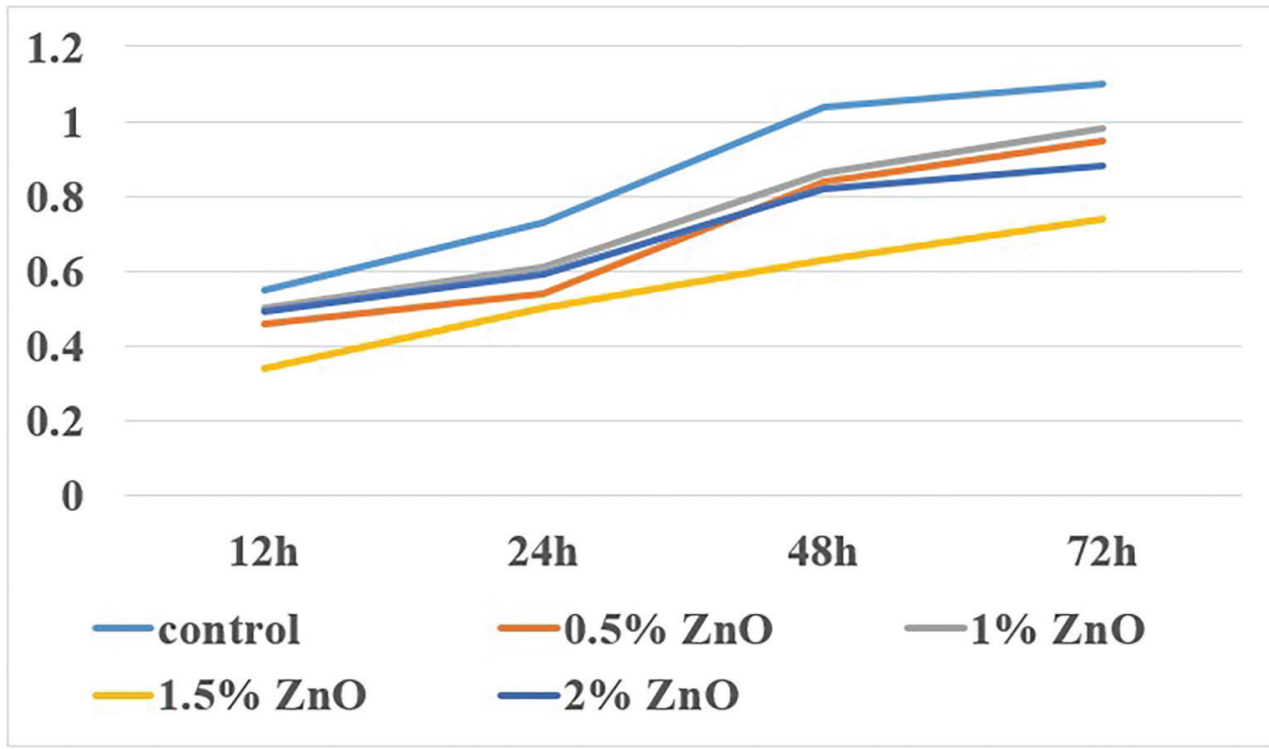

Fig. 3 Curve of mean of $\Delta E^{*}$ of all five groups (control group, $0.5,1.0,1.5$, and $2.0 \%$ by weight of nano zinc oxide) at each aging period.

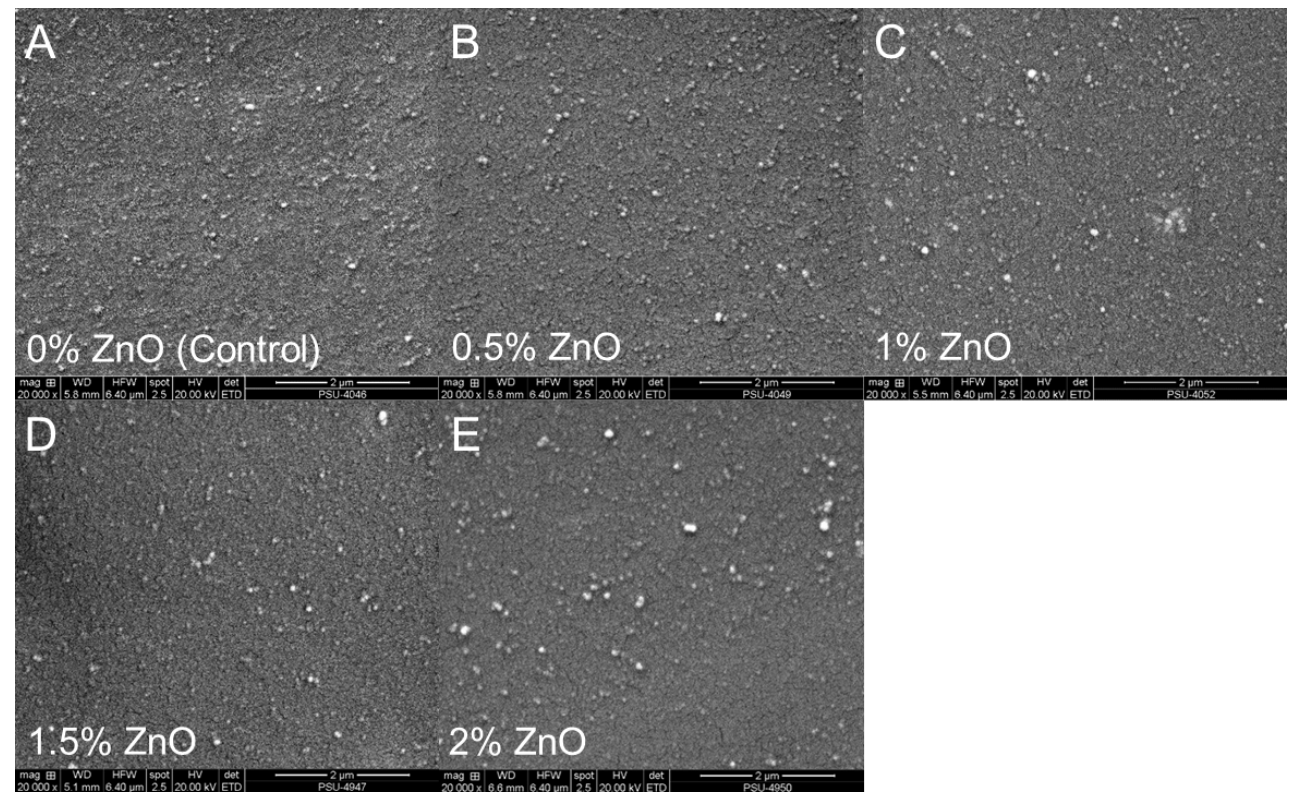

Fig. 4 Surface morphology of silicone elastomer samples under scanning electron microscopy (SEM).

test groups, the $1.5 \%$ group showed significantly lower $\Delta E^{*}$ compared with others, but the $\Delta E^{*}$ of the $0.5,1.0$, and $2.0 \%$ groups were not significantly different. The results indicated that the effects of two factors (concentration and aging time), as well as all the possible interactions between them, were statistically significant $(p<0.05)$. The concentration of nano zinc oxide was the factor that significantly $(p<0.05)$ affected the color stability at each period. All test groups had $\Delta E^{*}$ values of less than 1.0 but the $\Delta E^{*}$ of the control group at the aging time of 48 and 72 hours exceeded 1.0.

Silicone elastomer test samples were examined in scanning electron microscopy (SEM) (-Fig. 4). SEM images showed the well distribution of the nano oxides (white dots) and silicone pigments in the silicone matrix (-Fig. 4B-D). When the concentrations of the nano zinc oxide were $2 \%$ by weight, the particles seem to partly conglomerate ( - Fig. 4E).

\section{Discussions}

The environmental factor, UV, water, temperature, and humidity significantly affect the material's colors by enhancing the general degradation of polymers. ${ }^{18}$ The UV rays may cause a photooxidative attack with the collective action of the oxygen which may cause the breakdown of chain bonds decomposing the elastomer. ${ }^{19}$ This phenomenon leads to the rupture of the molecule which leads to degradation of the material, color changes, loss of opacity, and increased stiffness. ${ }^{20}$ The color change is dependent on the duration, extent, and intensity of the UV exposure. ${ }^{21}$ Gary and Smith ${ }^{11}$ stated that color changes in the early stage may be due to the degradation of certain UV light-susceptible pigments but longer term color change may be due to the intrinsic changes in the silicone. In our study, the mean of $\Delta E^{*}$ increased with artificial aging using UVA in all groups. 
The dental stone color mold can also affect the silicone color because the colorants that were added to the gypsum color product leach into the silicone. ${ }^{22}$ In our study, the silicone elastomers were processed in a stainless steel mold and vulcanized at room temperature to control the confounding factors on the color value.

Various authors in the past attempted the addition of UV stabilizers, thermochromic pigment, and opacifiers to improve the color stability of pigmented elastomers, but the outcome of these studies have been inconclusive. ${ }^{18,23}$ Kantola et al $^{18}$ observed that thermochromic pigments were sensitive to UV radiation and lead to color instability. Therefore, it can be concluded that thermochromic pigments are not suitable for prosthetic applications. The UV stabilizer includes UV absorbers and amine light stabilizers. UV stabilizers have been used routinely in the past to increase the shelf-life and prevent color degradation of products such as polymers, wood, cellulose fabrics, and paints. ${ }^{24}$ The study of Kheur et $\mathrm{al}^{25}$ found that the addition of a UV stabilizer, Chimassorb, led to a further reduction in color change of the pigmented elastomer.

There are two types of opacifiers, organic and inorganic. The inorganic colorants are metallic oxides. ${ }^{26}$ The inorganic colorants in this study are nano zinc oxide which has small particle size, large specific area, and strong interfacial interaction with the polymer. ${ }^{27}$ Hence, they are resistant to environmental stress cracking and aging. ${ }^{28}$

Organic pigments are derived from carbon and hydrogen, whereas inorganic pigments are from minerals in origin, and they contain metal atoms. Organic pigments have a short life span and are prone to deteriorate with exposure to the environment. ${ }^{11}$ Inorganic pigments were used in this study due to its color stability. The colors mostly used to mimic the patient's skin color are white, red, and yellow, which the authors also used in the study.

In this study, the percentage of nano zinc oxide affecting color stability was different for colors. The nano zinc oxide with $1.5 \%$ weight in the white group and the 1.5 and $2 \%$ weight in the yellow group and the 0.5 to $1 \%$ weight in the red group showed the least color change. Among the three colors, white pigments had the greatest color changes. Prosthesis with more white pigments may encounter more color changes than patients requiring less white colorant. Therefore, clinicians should be aware that when using a white silicone intrinsic pigment, it may create a color change effect on MDX4-4210. However, zinc oxide nanoparticles can be used instead of white color. Red and yellow pigments are commonly used in color formulations to obtain skin colors. In this study, these two pigments were not significantly different in the color change. This result is contrast with previous findings by Kiat-Amnuay et $\mathrm{al}^{29}$ and Beatty et $\mathrm{al}^{10}$ found that red pigments degraded to a larger extent than yellow. This could be due to the different types of colorants used. In maxillofacial prosthesis work, combinations in colors are needed to simulate the patient's skin color so an efficient amount of nano zinc oxide was calculated in part II with two-way repeated ANOVA by setting the color for the covariate factor. The results revealed that the most effective concentration of nano zinc oxide was $1.5 \%$, which had a $\Delta E^{*}$ value of less than 0.73 .
Also, the concentrations of nano zinc oxide can lessen the color change significantly compared with the control. These results confirmed that nano zinc oxide can efficiently prevent the color change of MDX4-4210 silicone. When the silicone is exposed to UV light, some parts of light are dispersed, and some are grasped by zinc oxide particles because the UV wavelength is bigger than the nanoparticle size. Because of these actions, UV protection is due to the absorption and scattering of nanoparticles. ${ }^{30}$ Since the nano oxide particles are extremely small and homogeneously dispersed in the silicone matrix, they are less likely to show migration and thereby exhibit greater color stability. ${ }^{31}$ The outcome supports the finding of Kiat-Amnuay et al, ${ }^{29}$ who demonstrated that the intrinsic coloring and opacifiers in a MDX4-4210 silicone could protect color change over time, as did Han et al, ${ }^{31}$ who found that filling nano oxides (nano- $\mathrm{CeO}_{2}$ and 2 and $2.5 \%$ nano- $-\mathrm{TiO}_{2}$ ) into facial silicone did help to improve color stability of silicone A-2186. But Nada et al $^{32}$ found contrast results as they demonstrated that nanoparticle groups exposed to UV light increased in color change compared with the control, and the more the concentration of nanoparticles, the more the color changed. A possible explanation for this could be that the concentration of nanoparticles in their study was too high $(\geq 2 \%)$ which increased the agglomeration resulting in the weak distribution in the elastomer matrix. Still, high agglomeration also decreases UV protection. ${ }^{33}$ According to this study, the $2 \%$ group had more color change than the $1.5 \%$ group. This is proven by SEM which showed that the particle of the $2 \%$ group was agglomerate, but other groups were well distributed. However, in this study, it showed that color change was of a small value, ranging from 0.73 to 1.10 at the aging time of 72 hours. Only the control group presented $\Delta E^{*}>1.0$, therefore $\Delta E^{*}$ below 1 is less likely than the visual level of perceptibility. The slight change in color may be due to the antioxidants and/or UV light stabilizers in silicone elastomers from manufacturing. ${ }^{34}$

Nanosized oxide particles also help to improve the properties of silicone elastomers as a filler reinforcement in a silicone matrix. Han et al indicates that addition of $\mathrm{Ti}, \mathrm{Zn}$, or Ce nano oxide at 2.0 to $2.5 \%$ by weight into silicone elastomers (Cosmesil M511) can improve the mechanical properties including tensile and strength, hardness, and elongation. ${ }^{33}$

Hence, nano zinc oxides can potentially be used with MDX4-4210 silicone as alternative opacifiers especially with a concentration of $1.5 \%$ weight. But the current study evaluated only the use of nano zinc oxide in resisting the color change; hence, a future study can be done to study the effects of nano zinc oxide on the mechanical properties of MDX4-4210.

Goiato et $\mathrm{al}^{35}$ evaluated the tear strength of MDX4-4210 and A-2186 silicones with different intrinsic pigments incorporated by mechanical and industrial methods, comparing nonaged and aged groups. They found that accelerated aging did not influence the tear strength of all aged A-2186 silicones and in aged pink industrial and mechanical MDX4-4210 silicones. The other MDX4-4210 groups had an increase in the results after aging. In all cases compared, the A-2186 group had higher tear strength values than the MDX4-4210 group. Mechanical and industrial methods can be used for silicone preparation, without changing the tear strength. 
Cifter et $\mathrm{al}^{36}$ investigated the effect of time passage, processing temperature, and molding-stone color on the color change of maxillofacial silicone elastomers, and they found that vulcanization temperature or the color of the molding stone has a significant effect on the color change over time. The molding-stone color and vulcanization temperature both affect the degree of color change after storage in a dark environment. The $L^{*}, a^{*}$, and $b^{*}$ values for the maxillofacial silicone elastomers are influenced by the direction of the increase or decrease according to the selected color and this effect varies as the temperature increases.

The limitation of this study is that all the specimens were subjected to artificial aging using a QUV chamber for only 12 , 24,48 , and 72 hours. The longer aging duration may affect the color change.

\section{Conclusions}

Both intrinsic coloring and zinc oxide nanoparticles affected the color of the silicone elastomer. Incorporation of zinc oxide nanoparticles at 0.5 to $2.0 \%$ in facial silicone MDX4-4210 can improve the color stability and $1.5 \%$ zinc oxide showed the most color stability.

\section{Availability of Supporting Data}

Supporting data are available on request.

\section{Authors' Contributions}

D.C. performed the research, analyzed the data, and prepared the manuscript. S.S. designed the research, supervised the research, analyzed the data, and reviewed the manuscript.

\section{Funding}

This research was supported by the Maxillofacial Prosthodontics and Dental Materials Research Unit, Faculty of Dentistry, Prince of Songkla University, Thailand.

\section{Conflict of Interest}

None declared.

\section{Acknowledgment}

We would like to acknowledge Maxillofacial Prosthodontics and Dental Materials Research Unit, Faculty of Dentistry, Prince of Songkla University, Thailand.

\section{References}

1 Beumer J, Marunick MT, Esposito S, Maxillofacial Rehabilitation: Prosthodontic and Surgical Management of Cancer-related, Acquired, and Congenital Defects of the Head and Neck 3rd ed. Illinois: Quintessence Publishing; 2011

2 Jani RM, Schaaf NG. An evaluation of facial prostheses. J Prosthet Dent 1978;39(5):546-550

3 Amornvit P, Rokaya D, Sanohkan S. Applications of PEEK in implant retained finger prosthesis. J Int Dent Med Res. 2019;12(4):1606-1609

4 Amornvit P, Rokaya D, Keawcharoen K, Raucharernporn S, Thongpulsawasdi $\mathrm{N}$. One- vs two stage surgery technique for implant placement in finger prosthesis. J Clin Diagn Res 2013;7(9):1956-1968

5 Nobrega AS, Malavazi EM, Melo Neto CLM, et al. Influence of different pigment incorporation methods on color, dimensional stability, and detail reproduction of silicones. Eur J Dent 2019;13(3):399-404

6 Anitha KV, Behanam M, Ahila SC, Jei JB. A custom made intrinsic silicone shade guide for Indian population. J Clin Diagn Res 2016;10(4):ZC27-ZC30

7 Mehta S, Nandeeshwar DB. A spectrophotometric analysis of extraoral aging conditions on the color stability of maxillofacial silicone. J Indian Prosthodont Soc 2017;17(4):355-360

8 Cantor R, Webber RL, Stroud L, Ryge G. Methods for evaluating prosthetic facial materials.J Prosthet Dent 1969;21(3):324-332

9 Watson RM, Coward TJ, Forman GH. Results of treatment of 20 patients with implant-retained auricular prostheses. Int J Oral Maxillofac Implants 1995;10(4):445-449

10 Beatty MW, Mahanna GK, Dick K, Jia W. Color changes in dry-pigmented maxillofacial elastomer resulting from ultraviolet light exposure. J Prosthet Dent 1995;74(5):493-498

11 Gary JJ, Smith CT. Pigments and their application in maxillofacial elastomers: a literature review. J Prosthet Dent 1998;80(2):204-208

12 Andreotti AM, Goiato MC, Moreno A, Nobrega AS, Pesqueira AA, dos Santos DM. Influence of nanoparticles on color stability, microhardness, and flexural strength of acrylic resins specific for ocular prosthesis. Int J Nanomedicine 2014;9:5779-5787

13 Goiato MC, Pesqueira AA, dos Santos DM, Antenucci RM, Ribeiro Pdo. Evaluation of dimensional change and detail reproduction in silicones for facial prostheses. Acta Odontol Latinoam 2008;21(1):85-88

14 dos Santos DM, Goiato MC, Moreno A, Pesqueira AA, Haddad MF. Influence of pigments and opacifiers on color stability of an artificially aged facial silicone. J Prosthodont 2011;20(3):205-208

15 Beltrami R, Ceci M, De Pani G, et al. Effect of different surface finishing/polishing procedures on color stability of esthetic restorative materials: a spectrophotometric evaluation. Eur J Dent 2018;12(1):49-56

16 Ceci M, Viola M, Rattalino D, Beltrami R, Colombo M, Poggio C. Discoloration of different esthetic restorative materials: a spectrophotometric evaluation. Eur J Dent 2017;11(2):149-156

17 Ergun G, Nagas IC. Color stability of silicone or acrylic denture liners: an in vitro investigation. Eur J Dent 2007;1(3):144-151

18 Kantola R, Lassila LVJ, Tolvanen M, Valittu PK. Color stability of thermochromic pigment in maxillofacial silicone. J Adv Prosthodont 2013;5(2):75-83

19 Eleni PN, Krokida M, Polyzois G, Gettleman L, Bisharat GI. Effects of outdoor weathering on facial prosthetic elastomers. Odontology 2011;99(1):68-76

20 Nobrega AS, Andreotti AM, Moreno A, Sinhoreti MA, Dos Santos DM, Goiato MC. Influence of adding nanoparticles on the hardness, tear strength, and permanent deformation of facial silicone subjected to accelerated aging. J Prosthet Dent 2016;116(4):623-629.e1

21 Lemon JC, Chambers MS, Jacobsen ML, Powers JM. Color stability of facial prostheses. J Prosthet Dent 1995;74(6):613-618

22 Cifter ED, Ozdemir-Karatas M, Baca E, et al. Effect of vulcanization temperature and dental stone colour on colour degradation of maxillofacial silicone elastomers. BMC Oral Health 2017;17(1):72

23 Kiat-amnuay S, Johnston DA, Powers JM, Jacob RF. Color stability of dry earth pigmented maxillofacial silicone A-2186 subjected to microwave energy exposure. J Prosthodont 2005;14(2):91-96

24 Feldman D. Polymer weathering: photo-oxidation. J Polym Environ 2002;10(4):163-173

25 Kheur MG, Kakade D, Trevor CJ, Lakha TA, Sethi T. Effect of newly developed pigments and ultraviolet absorbers on the color change of pigmented silicone elastomer. J Indian Prosthodont Soc 2017; 17(4):395-400 
26 Haug SP, Andres CJ, Munoz CA, Bernal G. Effects of environmental factors on maxillofacial elastomers: part IV-optical properties. J Prosthet Dent 1992;68(5):820-823

27 Vengatesan MR, Mittal V.Surface Modification of Nanomaterials for Application in Polymer Nanocomposites: An Overview. In: Mittal V, eds. Surface Modification of Nanoparticle and Natural Fiber Fillers. New Jersey: John Wiley \& Sons; 2015:1-27.

28 Cao Z, Zhang Z, Wang F, Wang G. Synthesis and UV shielding properties of zinc oxide ultrafine particles modified with silica and trimethyl siloxane. Colloids Surf A Physicochem Eng Asp 2009;340(1):161-167

29 Kiat-Amnuay S, Mekayarajjananonth T, Powers JM, Chambers MS, Lemon JC. Interactions of pigments and opacifiers on color stability of MDX4-4210/type A maxillofacial elastomers subjected to artificial aging. J Prosthet Dent 2006;95(3):249-257

30 Li R, Yabe S, Yamashita M, et al. UV-shielding properties of zinc oxide-doped ceria fine powders derived via soft solution chemical routes. Mater Chem Phys 2002;75(1):39-44
31 Han Y, Zhao Y, Xie C, Powers JM, Kiat-amnuay S. Color stability of pigmented maxillofacial silicone elastomer: effects of nano-oxides as opacifiers. J Dent 2010;38(Suppl 2):e100-e105

32 Nada HE, Ahmad MA, Moustafa NA. Evaluation of intrinsic color stability of facial silicone elastomer reinforced with different nanoparticles. Alex Dent J. 2016;41(1):50-54

33 Han Y, Kiat-amnuay S, Powers JM, Zhao Y. Effect of nano-oxide concentration on the mechanical properties of a maxillofacial silicone elastomer. J Prosthet Dent 2008;100(6):465-473

34 Craig RG, Koran A, Yu R, Spencer J. Color stability of elastomers for maxillofacial appliances. J Dent Res 1978;57(9-10):866-871

35 Goiato MC, Nobrega AS, Freitas da Silva EV, et al. Tear strength analysis of MDX4-4210 and A-2186 silicones with different intrinsic pigments incorporated by mechanical and industrial methods. Int J Dent 2019;2019:2573095

36 Cifter ED, Ozdemir-Karatas M, Cinarli A, Sancakli E, Balik A, Evlioglu G. In vitro study of effects of aging and processing conditions on colour change in maxillofacial silicone elastomers. BMC Oral Health 2019;19(1):122 